\title{
IELTS Speaking Instruction through Audio/Voice Conferencing
}

\section{HAMED GHAEMI}

Islamic Azad University, Gonabad Branch, Gonabad, Iran

hamedghaemi@ymail.com

\section{HOSSEIN KHODABAKHSHZADEH}

Islamic Azad University, Torbat-e-Heydarieh Branch, Torbat -e-Heydarieh, Iran

hkhodabakhshzade@gmail.com

\section{Bio Data:}

Hamed Ghaemi is a PhD candidate in TEFL at University of Tehran, Kish International Campus, Iran. He is a TEFL instructor at Azad University of Gonabad, Iran. His areas of research interests are Elearning, CALL, MALL, E-assessment, and ESP. He is currently the peer reviewer of the Journal of Online Learning and Teaching (JOLT).

Hossein Khodabakhshzadeh is a lecturer and PhD candidate in TEFL at Ferdowsi University of Mashhad, Iran. His current research interests cover issues in ELT, FLA and SLA. He has been involved in a range of projects in the area of applied linguistics, and has published several articles in internationally-refereed journals.

\begin{abstract}
The current study aims at investigating the impact of Audio/Voice conferencing, as a new approach to teaching speaking, on the speaking performance and/or speaking band score of IELTS candidates. Experimental group subjects participated in an audio conferencing class while those of the control group enjoyed attending in a traditional IELTS speaking class. At the end of the study, all subjects participated in an IELTS Examination held on November 2011 in Tehran, Iran. To compare the group means for the study, an independent t-test analysis was employed. The difference between experimental and control group was considered to be statistically significant $(\mathrm{P}<0.01)$. That is the candidates in experimental group have outperformed the ones in control group in IELTS speaking scores.
\end{abstract}

Keywords: Voice/Audioconferencing, IELTS Speaking Test, Speaking Skills, Needs analysis 


\section{Introduction}

Helping students to become skillful in a foreign language is the key aim of language teachers. Consequently, proficiency, defined as the level of competence attained by instruction (Omaggio Hadley, 2001), in all the skills of a language is of central significance in the field of second language acquisition. Over the time, different approaches have tried to achieve this goal by emphasizing different aspects of language learning.

Traditional approaches such as the grammar-translation method focused on grammatical precision through the clarification of grammar rules and memorization of vocabulary lists (Omaggio Hadley, 2001). Audiolingualism emphasized automatic response to linguistic stimuli using memorization, repetition, and pattern drills so that the target language reached the unconscious level of the mind (Omaggio Hadley, 2001).

In contrast with these conventional methods, communicative language teaching puts the emphasis on meaning and communication in the target language. This approach supports the development of communicative competence as the main goal of language teaching (Omaggio Hadley, 2001). Communicative competence has been defined as the particular skills of good communicators, such as negotiation of meaning or the use of proper context-specific register and style in written and spoken language (Savignon, 1997). Due to its emphasis on communication, this approach promotes attempts to communicate in the target language from the initial stages of instruction (Omaggio Hadley, 2001). It is therefore vital for language educators following this approach to supply learners with as many opportunities as feasible to communicate in the target language, in both written and oral forms. Oral proficiency is an essential aim of language teaching both from the methodological point of view and from the learner's perspective, either because of personal satisfaction, or occupational interests (Omaggio Hadley, 2001). Ommagio Hadley (2001) argues that it is the task of language teachers to recognize some helpful strategies for teaching spoken skills and to enhance the opportunities for developing oral proficiency. On the other hand, foreign language educators frequently experience difficulties in encouraging all students to take part candidly in oral activities, thus resulting in a slower growth of their communicative competence in spoken language.

The 1990s have seen a full-scale progress in the direction of communicative language teaching, with an emphasis on student engagement in authentic, contextualized discourse. Within this general communicative trend, we can note two diverse perspectives, both of which have their implications in terms of how to incorporate technology into the classroom. These can approximately be divided into cognitive approaches and sociocognitive approaches. Cognitive approaches to communicative language teaching are founded on the belief that language learning is a unique psycholinguistic procedure. Based on this point of view, language learners make a mental representation of a language system, based not on habit formation but on inherent cognitive knowledge dealing with comprehensible, meaningful language. Errors are not seen as bad behaviors to be avoided but as natural consequences of learning process that entails rule simplification, generalization, and transfer. A learner's output is valuable mostly to the extent that it 
helps make input more comprehensible so that the learner can build his or her own knowledge of the language.

Technologies supporting a cognitive approach to language learning are those that permit learners utmost chance to interact within meaning-rich contexts through which they build and obtain competence in the language. Instances of these kinds of technologies include text-reconstruction software, concordance software, and telecommunications.

Sociocognitive approaches put emphasis on the social facet of language acquisition; language learning is viewed as a process of socialization into particular communities (Schieffelin \& Ochs, 1986). From this perspective, students require to be given highest opportunity for authentic social interaction, not only to supply comprehensible input but also to give students carry out types of communicative tasks they will later need in outside the classroom. This can be accomplished through student collaboration on authentic tasks (see for example Breen, 1987; Candlin \& Murphy, 1987; Long \& Crookes, 1992; Prabhu, 1987 as cited in Warschauer, M. and Meskill, C., 2000) while concurrently learning both content and language (see for example Flowerdew, 1993; Meskill, (in press); Snow, 1991 as cited in Warschauer, M. and Meskill, C. 2000).

\section{Current Telecommunication System Use}

There are varieties of conferencing systems that presently exist: audioconferencing; audiographic conferencing; and desktop conferencing. The distinctions are: audioconferencing provides audio communication to connect participants over the telephone; audiographic conferencing merges audioconferencing and dataconferencing using the Internet to distribute data for collaboration among participants; and desktop conferencing utilizes a computer to link participants via the Internet to other PCs or telephones (Russ, M., 1997).

Conference calls are divided into two forms: regular basis calls and ad hoc basis calls. Regular basis calls comprise monthly progress report meetings and ad hoc basis ones are utilized throughout a company crisis such as sabotage (Gibson, D.L., Pauley, D., and Willis, L. 1997).

Since 1990 over one million conference calls have been completed in the US including features such as audio taping, sub-conferencing, and question and answer queuing (Martin, P.D., 1998).

In 1989, an ISDN network became operational in Germany that made threeway calls achievable and now up to ten-way party calls are feasible (Gleissert, J., April 1998).

\section{Important Features of an Audio Communication System}

Ackerman et al. (Ackerman, M.S., Hindus, D., Mainwaring, S.D., Starr, B., 1997) recognize definite characteristics as crucial for any type of audio conference system. These are constant open-audio microphones to facilitate long-term communication (Dourish, P. Adler, A., Bellotti, V., and Henderson, A., 1996) and make interaction more smooth (Gaver, W.W., 1993); good quality audio without a delay in voice transmission, which is essential for distant collaboration (Olson, J.S., Olson, G.M., and Meader, D.K., 1995) and comfortable use that permits use of accessing and 
leaving the system, which facilitates normal conversations in the workplace (Whittaker, S., D. Frohlich and O. Dalz-Jones, 1995).

Other features that may well be added to audioconferencing systems to boost the overall conference quality consist of 'voice activity detectors' that execute a microphone muting function and specify the current speaker (Gibson, D.L., Pauley, D., and Willis, L., 1997). Knowing who is speaking is important and well as the ability to have private conversations (Hindus, D., Ackerman, M.S. Mainwaring, S. and Starr, B., 1996).

\section{What Is Audio/ Voice Conferencing?}

Audio refers to sound and conference refers to a meeting. Audio conferencing usually refers to meetings held by people in different situations utilizing devices that allow sounds to be sent and received. These meetings may only engage two parties, but in many cases, there are several parties involved.

Audio conferencing permits numerous parties to connect using instruments such as phone. This can be a solution for problems that can occur when multiple groups need to meet. People who are distant and busy are not obliged to travel for long time since the meeting can be conducted from a near phone. There are several methods and technologies that support audio conferencing. Many telephone companies offer the capacity of three-way calling. This allows an individual to call two other people on separate lines and join them to form a group. Telephone audio conferencing happens when one side contacts a conferencing service.

Conferencing services offer different features to their customers that can make telephone audio conferencing an even more attractive choice. Participants may be able to record and replay all or definite parts of the meeting.

Audio conferencing can also be carried out using a computer and the Internet. If a person is only listening, he will only need speakers. If he would like to speak, he will require a microphone as well.

More stylish services proffer online audio conferencing options recognized as virtual meeting rooms. These may be accessed by various people without the host or the present participants being required to do an action. A virtual meeting room frequently offers useful features such as the facility to make visual presentations, share files, and to let private messaging among participants.

\section{Why Use Audioconferencing?}

Audioconferencing is a synchronous technology that requires simultaneous participation. Students can meet in small face-to-face groups and be connected as groups, rather than as individuals, using the telephone. Audioconferencing includes a level of interaction to the distance learning environment. This needs to be cautiously considered before commencing to use audioconferencing as part of any educational system. There are alternatives such as emails and Internet discussion boards, which smooth the progress of interaction without limiting learner independence and flexibility.

As with any teaching technology or method, it is vital to recognize the justification for using audioconferencing. By being clear about this, we can 
determine how we will use audioconferencing and what our exact objectives for using it are.

Many of the learning activities generally used in face-to-face teaching can be translated into the audio conference setting. The following are some of the kinds of activities we might consider to use in audioconferencing environment:

- Review and discussion of activities taken from course materials

- Set projects for whole group or small group work

- Student presentations

- Various forms of role play

- Brainstorming activities.

Most of these practices work best in a situation where students are participating in small groups, rather than separately dialing in from their own telephones. The appropriateness of any particular activity depends on the instructional design and other parameters we are working within. Some research into what would work best for our specific conditions is needed before starting an audioconferencing project.

The first step in planning an audio conference, or an audioconferencing system, is to set up its parameters. This involves asking:

- What instructional design will be taken up?

- Is audioconferencing an obligatory or optional part of the course?

- How many students are estimated to participate?

- Will students be dialing individually or in groups?

- How long are the sessions?

The answers to the above questions will help find out what activities will be effective. Other approaches might then become indispensable, such as utilizing print complementary material or data-conferencing with an interactive whiteboard. Table 1 depicts the advantages and drawbacks that ought to be considered when taking audio conferencing into account.

Table 1

\begin{tabular}{|ll|}
\hline \multicolumn{1}{|c|}{ ADVANTAGES } & \multicolumn{1}{c|}{ DISADVANTAGES } \\
\hline Relatively Not Expensive & Not as high Tech \\
Appeals to audio learner & Limited visual stimulation \\
Can combine with other media & need someone at site to coordinate \\
Site coordinator not needed & Facilitator needs to control many locations \\
Accessibility & Asynchronous communication \\
\hline
\end{tabular}

\section{Voice Conferencing in Language Teaching}

The past decade has seen an increasing number of researches on the use of audio or audiographic conferencing (Kenning 2010, p.4), for foreign language learning. In the past five years online language learning has concentrated on the use of audio and audiographic conferencing.

In the present era, the position of audio conferencing services has achieved scrupulous significance in the field of distance learning. This is where audio conferencing has offered a virtual meeting solution for individuals to the benefit of distance language courses presented in different countries. 
One of the key benefits offered by phone conferencing is that it has brought about the ease of bringing together students located at different geographical locations. Through phone conferencing, an individual dwelling in one country can avail of the teaching services presented in another country. This is principally relevant in case of language courses because the students are able to learn from individuals who are professional on that language.

Since audio conferencing services do not engage a face to face interaction, individuals who are a hesitant can also take advantage of it. Instructors can make use of this fact to build up a teaching methodology that involves well interaction, thus enhancing the student's interactive skills together with his linguistic skills.

Learning a new language involves continuous feedback from the instructor to make sure that the accurate way of writing \& pronunciation is being comprehended. A two-way phone conferencing facility ensures that the teachers are able to pursue the improvement of their students and can provide instant feedback to improve their learning process. This is one of the most important reasons for the growing use of audio conferencing in distant language courses.

By providing a virtual meeting, audio conferencing offers an interactive platform for not only students but also for the instructors. Customary interaction between the instructors would permit for an exchange of ideas concerning the teaching methodologies. This would significantly benefit the students around the world by giving them a common learning platform.

Audio conferencing services have altered the way distance language courses are being presented nowadays, however its function does not end here. Audio conferencing can be integrated with video conferencing to produce a close duplication of a face to face interaction. Instructors would be able to build a virtual classroom environment that would be more beneficial to learning. Further, the use of internet based conferencing would also permit for exchange of study material between the students and teachers. Therefore, as we can see the utilization of audio conferencing in distance language learning is just the beginning since innovations in the realm of web conferencing continue to take place.

\section{Research Questions and Hypothesis}

The current study attempts to investigate the following research questions:

1 - Does Voice/Audio - conferencing improve the speaking performance of IELTS candidates?

2 - Based on the subjects' needs analysis, can audio-conferencing be an upcoming trend in teaching Speaking skills for would-be IELTS candidates?

To be on the safe side, and according to the above-mentioned questions, the following null hypothesis was developed:

Audio/Voice conferencing doesn't have any influence on the IELTS candidates' speaking performance.

\section{Instruments}

The present study enjoys the use of Audio-conferencing service provided by MTN Irancell in Iran. Irancell is the third mobile phone network operator of Iran. It is $49 \%$ owned by the South Africa-based MTN Group. MTN Irancell operates on GSM $900 / 1800$ and is the first network operator of Iran which provides GPRS and MMS 
service. Another important instrument employed in the study was an IELTS Speaking Test provided by the British Council in Iran.

\section{Procedures}

At the beginning of the study four IELTS candidates, who have previously participated in the IELTS Examination in Iran but couldn't obtain their desired score, were selected. The selection procedure consisted of consulting and discussing with these four candidates about the problems they have encountered during their speaking test. All candidates obtained the speaking band score of 4.5 in their previous attendance in IELTS Examination. Then the researcher talked to them about the proposed way of teaching speaking, i.e. Voice/Audio conferencing and suggested them to participate in this virtual classroom. None of the candidates was aware of participating in a research, they have only being informed that this new approach to teaching speaking is completely virtual and they don't need to attend any kind of IELTS speaking classes, and they are never required to pay any amount of money for their participation. At the beginning of the consultation the candidates imagined that they have to pay money or their cell phone bill will be charged, but the researcher has persuaded them that use of voice conferencing will only charge the first caller, that is the teacher. Therefore, all the candidates were quite satisfied and agreed to participate in the study.

The control group subjects, who were 7 students, were selected based on their overall score in the IELTS sample placement test of the institute. Investigating about their speaking band score, the researcher found that the mean of their speaking band score was 4.

The teacher, who was the researcher himself and was the teacher of the control group too, is one of the most experienced IELST instructors in Mashhad, Iran and is the head of IELTS department at the Jahan Elm Higher Education Institute where the research was conducted. The instructor has participated in the IELTS Examination in 04/09/2009 and obtained the overall score of 8 in academic module with the speaking band score of 8 . So, he could be considered as a good choice for handling the virtual IELTS Speaking class via audio conferencing carried out in the study.

The first session of the class was arranged by the teacher and his four IELTS candidates. The time of the class was predetermined by the teacher and agreement of the candidates and they agreed upon to start the class at 9 o'clock a.m. Exactly at 9 o'clock the teacher called the first candidate and after some seconds he could call the other three candidates simultaneously. At the beginning of the class all candidates were surprised and shocked, since they haven't had any same experience about virtual classes or audio conferencing, therefore, the teacher talked to them for about 10 minutes and explained to them the benefits and advantages of participating in audio conferencing classes. At around 9:15 the first session of the class was commenced formally.

Exactly the same activities and procedures which were supposed to be covered and worked on in the control group were covered and worked on in the experimental group. 
Both control and experimental groups were supposed to attend the class for 10 sessions, two sessions in each week. The main objective of the IELTS Speaking classes were to (a) introduce the IELTS speaking test to the candidates, (b) clarify the three main phases of IELTS speaking test, (c) teach the speaking strategies that could increase the score of the candidates and tell them how to employ these strategies, (d) and give ample time to the candidates to speak about the topics and questions that were likely to appear in the IELTS Speaking test. The subsidiary aims of the teacher was to provide the students with sufficient information about the assessment criteria used in the IELST speaking test, so that students could be completely cognizant about the way their speaking performance was going to be assessed.

Having participated in the audio conferencing, i.e. experimental group and traditional classes, i.e. control group for ten sessions, the four candidates of experimental group and five out of seven candidates of control group decided to participate in IELTS Examination on November Fourth in Tehran, Iran. The results of the test are available online at http://ielts.sanjesh.org/OnlineResults.aspx

\section{Data collection and Analysis}

As mentioned in the previous section, the speaking band scores of the experimental group subjects obtained from their previous attendance in IELTS Examination were considered as the pretest for the experimental group. The speaking band scores of control group subjects who have participated in the IELTS sample test of the institute were regarded as the pretest for the control group. The results for the descriptive analysis of the pretests for experimental and control groups are shown in table 1.

Table 1

Mean score and Standard deviation for pretest

\begin{tabular}{cccl}
\hline Std. Deviation & Mean & N & $\begin{array}{l}\text { Group } \\
\text { Variables }\end{array}$ \\
\hline 0.548 & 3.65 & 5 & $\begin{array}{l}\text { Control } \\
\text { Group }\end{array}$ \\
0.727 & 3.95 & 4 & $\begin{array}{l}\text { Experimental } \\
\text { Group }\end{array}$ \\
\hline
\end{tabular}

The IELTS Examination held on November fourth in Tehran, Iran was regarded as the posttest. The Speaking band scores of the candidates in experimental and control groups were considered as posttest. Table 1 illustrates the results of posttest for experimental and control groups.

Table 2

Mean score and Standard deviation for posttest

\begin{tabular}{rcccl}
\hline $\begin{array}{l}\text { Std. Error } \\
\text { Mean }\end{array}$ & Std. Deviation & Mean & N & $\begin{array}{l}\text { Group } \\
\text { Variables }\end{array}$ \\
\hline 0.183 & 0.93 & 5.51 & 5 & Control Group \\
0.141 & 0.77 & 7.10 & 4 & $\begin{array}{l}\text { Experimental } \\
\text { Group }\end{array}$ \\
\hline
\end{tabular}


To compare the group means for the study, an independent t-test analysis was employed for posttest phase (see table 3). As shown in this table, the difference is considered to be statistically significant between the two experimental and control groups $(\mathrm{P}<0.01)$. That is the candidates in experimental group have outperformed the ones in control group in IELTS Speaking test scores.

Table 3

Independent Sample T-Test

\begin{tabular}{|l|l|c|c|c|c|c|c|c|c|c|}
\hline \multicolumn{2}{|c|}{} & \multicolumn{2}{|c|}{} & \multicolumn{7}{|c|}{} \\
\cline { 2 - 9 } & $\mathrm{F}$ & $\mathrm{Sig}$ & $\mathrm{t}$ & $\mathrm{df}$ & $\begin{array}{l}\text { Sig.(2- } \\
\text { tailed) }\end{array}$ & $\begin{array}{c}\text { Mean } \\
\text { Difference }\end{array}$ & $\begin{array}{c}\text { Std. Error } \\
\text { Difference }\end{array}$ & Lower & Upper \\
\hline $\begin{array}{l}\text { Speaking } \\
\text { Test }\end{array}$ & $\begin{array}{l}\text { Equal } \\
\text { variance } \\
\text { assumed } \\
\text { Equal } \\
\text { variances } \\
\text { not } \\
\text { assumed }\end{array}$ & 1.438 & 0.264 & 2.355 & 45 & 0.0117 & 0.650 & 0.643 & 0.138 & 0.142 \\
\hline
\end{tabular}

This confirms that Audio/Voice conferencing could be beneficial for improving IELTS Speaking performance and scores of candidates. Therefore, as can be seen, the previously-developed null hypothesis of the study is rejected.

Now let's consider the second question of the study. The researchers of the current study aimed to explore the students' perceptions about the usefulness, value and efficacy of audioconferencing as a future trend in teaching IELTS speaking skills or generally teaching speaking skills. That's why they have developed a questionnaire to do a needs analysis and find out about the subjects' perspectives. Having administered and analyzed the results of the questionnaire, the researcher found that almost all the subjects were in favor of having audioconferencing as a means of language instruction. The results of the questionnaire were not really surprising, since in the context of Iran almost all students whether IELTS candidates or EFL learners are greatly deprived from having such kinds of technologies. But the findings of the questionnaire were a great support for the results of the study.

\section{Discussion and Implications}

Many of the most widespread tasks in educational contexts can be done effectively by telephone. The audio medium is accessible, simple and cost effective in relation to more complicated technology, such as videoconferencing and interactive computer programs. Audioconferencing is also a learner-centered approach that can be effectively integrated with other media - for example, print. Moore (1994) provides an outstanding argument of the advantages of audio conferencing in an editorial column for The American Journal of Distance Education. Research recommends that audioconferencing is best matched with interactive work, where tasks are based on the oral exchange of participants. To augment the educational effectiveness of 
audioconferencing, teaching approaches that optimize its interactive potential must be developed. Many of the wide range of learning activities normally used in face-toface teaching can be changed into the audio conference environment. Various kinds of activities can be considered as the audio conferencing - based activities such as: students' presentations or debates, various forms of role play and brainstorming activities. Most of these activities work best in a situation where students are participating in small groups, rather than individually dialing from their own telephones.

The results of the present study confirm the findings of the previous research in the field of audioconferencing and its effectiveness in language learning procedure. However, the number of works done in this field is not remarkable. As demonstrated in this study the audioconferencing can be valuable for teaching speaking but its applicability is not proven for the other skills yet. Therefore, one of the great opportunities for the other researchers is to concentrate on the effect of audioconferencing on the other language skills and even components. Most of the IELTS candidates always complain about the insufficient amount of time they have to prepare them for the IELTS Examination, also they usually find attending the preparation classes a very difficult and taught job. Therefore, if they can be provided with an instrument or with a method through which they can improve their speaking performance, or even other skills, without attending any kind of preparation class, they will welcome it with open arm. 


\section{References}

Ackerman, M.S., Hindus, D., Mainwaring, S.D., \& Starr, B. (1997). Hanging on the 'wire: A field study of an audio-only media space. ACM Transactions on Computer-Human Interaction, 4,1, 39-66.

Dourish, P. Adler, A., Bellotti, V., \& Henderson, A. (1996). Your place or mine? Learning from Long-term use of audio-video communication. Computer Supported Cooperative Work, 5(1), 33-62.

Gaver, W.W. (1993). Synthesizing auditory icons. In Proceedings of the ACM INTERCHI '93 Conference on Human Factors in Computing Systems, ACM, N.Y., 228-235.

Gibson, D.L., Pauley, D., \& Willis, L. (1997). Unattended audioconferencing. BT Technology Journal, 14(4), 26-32.

Gleissert, J. (April 1998). personal email correspondence; personal telephone call.

Hindus, D., Ackerman, M.S. Mainwaring, S. and Starr, B. (1996). Thunderwire: A field study of an audio-only media space. In Proceedings of CHI '96, ACM, N.Y., 238247.

Martin, P.D. (April 1998). Audio conference information (sprint). personal email correspondence.

Moore, M. (1994). Editorial - Audioconferencing in Distance Education. The American Journal of Distance Education, 8(1). Available from www.ed.psu.edu/acsde

Olson, J.S., Olson, G.M., \& Meader, D.K. (1995). What mix of video and audio is useful for small groups doing remote real-time design work? In Proceedings of the ACM Conference on Human Factors in Computing Systems (CHI'95). ACM, N. Y., 362-368.

Omaggio Hadley, A. (2001). Teaching Language in Context (3 $3^{\text {rd }}$ ed.). Boston: Heinle \& Heinle.

Russ, M. (1997). Desktop conversations - the future of multimedia conferencing. BT Technology Journal, 14, 42-50.

Savignon, S. J. (1997). Communicative competence: Theory and classroom practice. Texts and contexts in second language learning ( $2^{\text {nd }}$ ed.). Boston: McGraw Hill.

Schieffelin, B. B., \& Ochs, E. (1986). Language socialization. Annual review of anthropology, 15, 163-191.

Warschauer, M., \& Meskill, C. (2000). Technology and Second Language Teaching and Learning. in J. Rosenthal (Ed.), Handbook of Undergraduate Second Language Education. Mahwah, NJ: Lawrence Erlbaum.

Whittaker, S., Frohlich, D., \& O. Dalz-Jones. (1995). Informal workplace communication: What is it like and how might we support it? In Proceedings of the ACM Conference on Human Factors in Computing Systems (CHI'95). ACM, N. Y., 369-376. 